\title{
Capital-Skill Complementarity and Biased Technical Change Across US Sectors*
}

\author{
Alejandro Perez-Laborda \\ Universitat Rovira-i-Virgili and CREIP
}

Fidel Perez-Sebastian

U. Alicante and U. Hull

August 2020

\begin{abstract}
The goal of this paper is two-fold. First, we reexamine the evidence for the capital-skill complementarity (CSC) and the skill-biased technological change (SBTC) hypotheses at the sectoral level in the US economy for the period 19702005. Second, we quantify their effect on the evolution of the wage skill premium. To do so, we estimate a translog model with three production factors (skilled labor, unskilled labor, and capital) for different sets of industry aggregates suggested by the literature. At the aggregated level, we find that both CSC and SBTC explain a substantial part of the observed change in the skill premium. The CSC hypothesis also receives support across sectors, although SBTC often explains a larger part of the premium change. We also find that the relevance of CSC increases with the level of aggregation of the data. Besides, when we disaggregate capital into ICT and non-ICT, our results suggest that often ICT capital is not the primary source of CSC. However, ICT-CSC is the most important driver of the skill premium in specific sectors, such as financial and business services.
\end{abstract}

JEL Classification: O40, O47

Keywords: Capital-skill complementarity, biased technical change, skill premium, labor share, translog, ICT capital.

${ }^{*}$ An earlier version of this work circulated under the name "Capital-Skill Complementarity and Bias of Technical Change across Sectors and Countries". This paper has benefited from the comments and suggestions of an anonymous referee, and from participants at conferences and seminars where it has been presented. The usual disclaimer applies. 


\section{Introduction}

Over the last 40 years, most developed economies have experienced a steady increase in the relative supply of skilled workers, which has not been accompanied by a deterioration of the skill premium. The wage gap between skilled and unskilled workers has even increased in some countries, such as the US.

Several works have postulated the existence of a latent technological change that is favoring skilled workers over the unskilled to explain this apparent contradiction. This skill-biased technical change (SBTC) has raised the productivity of the skilled over the unskilled, driving up the premium. Papers that defend this thesis include Bound and Johnson (1992) and Katz and Murphy (1992).

An alternative explanation is related to the decline of the relative price of the investment in equipment during the same years, which has led to a substantial increase in the use of capital in the workplace. If the Griliches (1969) capital-skill complementarity hypothesis (CSC) holds, and capital is more complementary to skilled than to unskilled labor, the observed increase in the quantity of capital may have raised the relative productivity of skilled labor and, thus, its relative wage (see, e.g., Krusell et al. 2000).

CSC and SBTC represent different characteristics of the production function. While CSC is related to the curvature of the isoquants, and hence, to the ease with which an input can be substituted by other input without changing the amount of output produced, SBTC originates from non-parallel shifts in those isoquants, which modify the relative productivity of the inputs. The validity of these hypotheses has core implications in growth, trade, and development, as argued, e.g., in Stokey (1996). ${ }^{1}$ Consequently, a battery of studies has looked for their empirical support (Acemoglu, 2002, makes an excellent review). While many works stress the importance of SBTC to explain skill premium changes, the evidence in favor of the CSC hypothesis has been much more elusive. For example, Fallon and Layard (1975), Krusell et al. (2000)

\footnotetext{
${ }^{1}$ Stokey (1996) shows that if CSC is the main force behind the increasing wage inequality, partially opening the economy to trade in capital goods with a larger and more developed economy has a much larger impact on the skill premium than full economic integration. The reason is that the emigration of unskilled workers to the developed country counteracts the change in skill premium caused by the movement of capital goods. The effects of these two trade-policy regimes are very different if, instead, SBTC is the main driving force of the skill premium.
} 
and Bergstrom and Panas (1992) document that capital is more complementary to skilled than to unskilled. Other papers, like Duffy et al. (2004) and Papageorgiou and Chmelarova (2005), find null or weak support for the CSC. On the contrary, SBTC has found plenty of support in the literature (see, e.g., Bound and Johnson, 1992; Katz and Murphy, 1992; Berman et al., 1998; Baller and van Reens, 2013).

Our work contributes to this literature by rigorously assessing the evidence for both the SBTC and the CSC hypotheses in several literature-suggested sets of industry aggregates of the US economy within an integrated empirical framework. Previous work generally focuses only on one of these two hypotheses, employing either manufacturing or completely aggregated data. The studies based on aggregated data, on the one hand, omit the large differences in input structures and technological progress of the different industries stressed, for example, by Jorgeson and Timmer (2011) and Herrendorf et al. (2015). This omission may mask meaningful relationships among inputs present at a lower aggregated level. On the other hand, studies based only on manufacturing data neglect the important role of the different service industries, which account for about three-quarters of the total value-added and hours worked in many developed economies. Our results also provide information about certain features of the production functions, such as the elasticity of input substitution and the importance of input-biased technological change, which are necessary for multi-sectoral models, nowadays employed to understand many economic issues of interest.

To assess the strength of the CSC and SBTC conjectures at the sector level, we use data from the EU KLEMS dataset and estimate a translog model specification for a set of representative sectors of the US economy suggested by Jorgeson and Timmer (2011). Following Valentinyi and Herrendorf (2008), we also investigate their empirical support in two-sector splits of the aggregate economy suggested by theoretical models. The great flexibility of the translog model allows for a more consistent characterization of the SBTC and CSC hypotheses in terms of the estimated parameters than alternative specifications like the CES or Cobb-Douglas production functions. Moreover, as shown in Ruiz-Arranz (2002), the translog can be employed to gauge the relative contribution of the CSC and SBTC to the observed growth in the skill premium, which is essential because both hypotheses may found support in the data.

Our work is closely related to Fallon and Layard (1975) and Richter (2013). Fallon 
and Layard use cross-sectional data to estimate reduced form equations derived from a two-level CES production function for a single year. They find mild (though statistically not significant) evidence in favor of the CSC hypothesis at the aggregate level but strong evidence at sector level. However, the authors do not have capital data for the different sectors and must rely on cross-sector efficiency. The EU KLEMS database contains detailed capital and labor numbers at a sector level; so, we can directly evaluate the CSC hypothesis allowing as well for differences in efficiency across sectors. Besides, the time dimension of the data gives us the possibility to accommodate SBTC, which is not considered in Fallon and Layard (1975). Richter (2013), in turn, carries out a translog analysis of the evolution of the wage skill premium in different 2-digit US industries. However, she neither tests for the CSC and SBTC hypothesis nor quantifies the role of other factors than ICT and technology on the evolution of the skill premium.

Our results can be summarized as follows:

1. At the aggregate level, there is strong evidence for both CSC and SBTC, with the two phenomena being equally important in explaining the observed trend in the skill premium.

2. At the sectoral level, the empirical support for the SBTC is strong in all sectors. The evidence for CSC is also wide, although not as much as for SBTC; that is, we find that the SBTC is often the most important driver of the skill premium. However, we also find that the contribution of CSC to the skill premium raises with the level of aggregation.

3. Regarding the sources of CSC, we find that non-ICT capital is usually its main source. Yet, CSC originated in ICT capital is essential to explain the skill premium pattern of specific sectors, such as financial and business services.

The paper is organized in the following way. Section 2 provides a theoretical example to understand the importance of sectoral analysis. Section 3 briefly describes the translog model. Section 4 discusses the empirical framework and describes the data. Section 5 presents the estimation results for a baseline translog specification with three inputs (skilled and unskilled labor, and capital) for the set of sectors discussed in 
Jorgenson and Timmer (2011). These results are extended in Section 6 by explicitly distinguishing between ICT and non-ICT capital, and also by considering two-sector splits of the aggregate economy common in the macroeconomic literature. Section 7 makes some concluding remarks.

\section{A Simple Model}

To illustrate the effect of sectoral differences on the skill premium, we can consider an economy composed of two sectors that use skilled labor $(S)$, unskilled labor $(U)$, and capital $(K)$ to produce two final goods $\left(Y_{1}\right.$ and $\left.Y_{2}\right)$ according to the following production function:

$$
Y_{i}=\left[\left(K_{i}^{\rho_{i}}+U_{i}^{\rho_{i}}\right)^{\sigma_{i} / \rho_{i}}+\left(A_{i} S_{i}\right)^{\sigma_{i}}\right]^{1 / \sigma_{i}}
$$

The elasticity parameters $\rho_{i}$ and $\sigma_{i}$ belong to the interval $(-\infty, 1)$. As the elasticity parameters increase, the degree of substitution between the associated inputs rises. It can be shown that CSC requires that $\sigma_{i}<\rho_{i}$, it is, capital is less substitutable for skilled than for unskilled. ${ }^{2}$ The variable $A_{i}$ captures the level of sector-specific skill-biased technical change.

Let us suppose, for simplicity, that $\rho_{i}>0$ and that the economy-wide supplies of skilled and unskilled workers are constant, whereas $A_{i}$ and $K_{i}$ can grow. Let us also denote by $w_{S}$ and $w_{U}$ the wage of skilled and unskilled workers, respectively. If all markets are competitive, wages will equal the marginal product of labor. It is easy to obtain that the wage skill premium will be equalized across sectors and given by:

$$
\frac{w_{S}}{w_{U}}=\frac{A_{i}^{\sigma_{i}}}{S_{i}^{1-\sigma_{i}}} \frac{U_{i}^{1-\rho_{i}}}{\left(K_{i}^{\rho_{i}}+U_{i}^{\rho_{i}}\right)^{\frac{\sigma_{i}}{\rho_{i}}-1}}, \quad \text { for } i=1,2 .
$$

The effect of SBTC can be observed in the numerator of equation (2). Its direction is going to depend on whether $\sigma_{i}$ is larger or smaller than zero. If skilled labor is a relative substitute of the capital-unskilled composite $\left(\sigma_{i}>0\right)$, a rise in $A_{i}$ will increase the skill premium. However, if they are relative complements $\left(\sigma_{i}<0\right)$, wage inequality will decrease with $A_{i}$. The impact of the CSC, on the other hand, works through capital. As $K_{i}$ goes up, so does the skill premium provided that $\sigma_{i}<\rho_{i}$, that is, if

\footnotetext{
${ }^{2}$ See, e.g., Duffy et al. (2004).
} 
and only if there is CSC. When $\sigma_{i}>\rho_{i}$, in turn, the wage ratio falls if the amount of capital rises.

But the elasticities of substitution among inputs can vary between the two sectors. If, for example, $\sigma_{1}>0>\sigma_{2}$, skill-biased technical change may not show up in the aggregate data as a driver of the skill premium, even though it has clear effects in each of the two sectors separately. More specifically, SBTC in sector one will push wage inequality up and attract additional skilled workers, while SBTC in sector two will push the wage ratio down and free skilled labor.

A similar argument can be used for CSC. If sector one displays strong CSC, and sector two strong capital-skill substitutability, we may not observe changes in the skill premium at the aggregate level even if capital is being accumulated rapidly in both sectors. The parameter restrictions, in this case, are $\sigma_{1}<\rho_{1}$ and $\sigma_{2}>\rho_{2}$. Capital accumulation in sector one will tend to raise the skill premium, and the sector will hire a larger amount of skilled labor. Sector two, on the other hand, will push wage inequality down and free skilled workers.

Which effect dominates at the aggregate level in each of these two scenarios will depend on the strength of technological progress and CSC in each of the two sectors. It will also depend on the industry weights in the total economy. For example, it is also perfectly possible that if the sector with the largest share depicts CSC, the aggregate economy shows evidence of capital skill complementarity even if there is an important sector (the other one) that does not. A sectoral analysis of the determinants of wage inequality is then essential to disentangle the contributions of CSC and SBTC better.

\section{The Translog Framework}

The joint assessment of both CSC and SBTC requires a sufficiently flexible framework. Christensen et al. (1973), among others, argues that the translog specification offers that flexibility and overcomes the drawbacks of the direct estimation of Cobb-Douglas or (nested) CES production functions. More specifically, the translog framework allows for separate estimation of the different elasticities of input substitution and the input biases of technology, so that the CSC and the SBTC hypothesis can be easily tested, and their different contributions to the evolution to the wage skill premium quantified. 
Moreover, unlike the alternative specifications mentioned previously - which assume that inputs are substitutes to ensure concavity - the translog imposes no prior restrictions over the substitutability or complementarity among production factors. It also allows for time-varying substitution elasticities.

As Christensen et al. (1973) explain, the translog production function can be interpreted as a second-order Taylor series approximation in logarithms to an unspecified underlying production function. Moreover, applying duality in production theory, we can characterize the production possibility frontier in terms of the price possibility frontier and work with the dual problem. That is, assume a translog specification for the price function.

Assuming in each sector constant returns to scale over hours worked by skilled $(S)$ and unskilled $(U)$ workers, and capital $(K)$, a three input translog price function can be written as (sectoral indices are omitted to simplify notation):

$$
\ln P_{t}=\alpha_{0}+\alpha_{p}^{\prime} \ln p_{t}+\alpha_{T} t+\frac{1}{2} \ln p_{t}^{\prime} B_{p p} \ln p_{t}+\ln p_{t}^{\prime} \beta_{p T} t+\beta_{T T} t^{2}
$$

where $P_{t}$ is the price of output in the sector, the vector $p_{t}$ contains skill and unskilled wages and the return to capital, and $t$ is a time trend. As standard in the literature, the time trend serves as a technology index (see, e.g., Jorgenson et al., 1987, Betts, 1997, Ruiz-Arranz, 2002, and Feng and Serletis, 2008). ${ }^{3}$

Factor shares $(v)$ can be obtained from equation (3) by applying Shephard's lemma:

$$
v_{t}=\frac{\partial \ln P_{t}}{\partial \ln p_{t}}=\alpha_{p}+B_{p p} \ln p_{t}+\beta_{p T} t .
$$

Notice that $B_{p p}$ is the matrix of share elasticities. The elements of this matrix give the response of the input shares to proportional changes in the input prices. If the $i j$ element is positive $\left(\beta_{i j}>0\right.$, where $\left.i, j \in\{S, U, K\}\right)$, the cost share of the input $i$ increases with the price of the input $j$, and the opposite effect arises if the element is negative. Expression (4) allows non-Hicks-neutral technological progress, so that factor shares are affected by technology advances. In particular, the vector $\beta_{p T}$ collects the possible bias of technical change of the four inputs. If the bias for input $i$ is positive (negative) then $\beta_{i T}>0\left(\beta_{i T}<0\right)$, the cost share of that input increases (decreases)

\footnotetext{
${ }^{3}$ Jin and Jorgenson (2010) adopt a different approach and model technological progress within the unobserved component framework, estimating the model with the help of the Kalman filter.
} 
with technology, and progress is input- $i$ using (saving). The additional properties of the theory of production can easily be translated into this framework as restrictions in the parameters. In particular, linear homogeneity and product exhaustion are satisfied if:

$$
\sum_{i} \alpha_{i}=1 ; \quad \sum_{j} \beta_{i j}=0 ; \quad \sum_{i} \beta_{i T}=0
$$

Symmetry requires:

$$
B_{p p}=B_{p p}^{\prime}
$$

Non-negativity of the factor cost shares implies that

$$
v_{t}=\alpha_{p}+B_{p p} \ln p_{t}+\beta_{p T} t \geq 0
$$

Finally, concavity holds if the Hessian matrix $(H)$ of second order derivatives of the translog unit cost function with respect to prices is negative semi-definite:

$$
h^{\prime} H h \leq 0 \quad \forall h, \quad \text { with } H=\left[\frac{\partial^{2} P}{\partial p \partial p^{\prime}}\right] .
$$

The SBTC and CSC hypothesis can be easily formulated in this framework in terms of model parameters. Specifically, the SBTC is satisfied if the bias of technical change for skilled labor is larger than the one of the unskilled, that is,

$$
\text { SBTC: } \quad \beta_{S T}-\beta_{U T}>0 \text {. }
$$

To state the CSC condition, we need first to define the elasticity between inputs. As shown in Binswanger (1974), the Allen-Uzawa partial elasticity of substitution (AES) between any pair of production factors can be computed directly from the parameters of the translog model as:

$$
\begin{aligned}
\sigma_{i j}^{A} & =\frac{\beta_{i j}+v_{i} v_{j}}{v_{i} v_{j}} \quad \text { if } i \neq j \\
& =\frac{\beta_{j j}+v_{j}^{2}-v_{j}}{v_{j}^{2}} \quad \text { if } i=j .
\end{aligned}
$$

If $\sigma_{i j}$ is positive (negative), an increase in the price of one input causes an increase (decrease) in the quantity demanded of the other, and factors are substitutes (complements) in production. As can be deduced from (10), in the translog framework the 
computation of the AES involves not only the estimated parameters but also the factor shares. ${ }^{4}$

Following Griliches (1969), we can write that the CSC hypothesis holds if:

$$
\text { CSC: } \sigma_{S K}^{A}-\sigma_{U K}^{A}<0 \text {. }
$$

Thus, evidence of CSC requires the difference between the elasticities of skilled and unskilled labor with respect to capital to be negative.

\section{Empirical Strategy}

\subsection{Data description}

Our primary source of data is the Standard-Industrial-Classification-based EU KLEMS database, March 2008 release, which contains detailed measures of labor and capital inputs at the NACE (Statistical classification of economic activities in the European Community), revision 1, for the period 1970 to $2005 .^{5}$ The length of the data is relatively short, but in line with the other single country studies in the literature (see, e.g., Katz and Murphy, 1992; Betts, 1997; Krusell et al., 2000; Ruiz-Arranz, 2003; Antras 2004). For a detailed description of this dataset, see O'Mahony and Timmer (2009).

The labor data contain detailed information on hours worked and compensations for three skill levels: high, corresponding to workers with tertiary education or more; medium, for workers not graduated from college but holding a secondary education diploma; and low, for workers without a high school degree. We divide labor into two categories: unskilled and skilled. Following Krusell et al. (2000), we classify the hours

\footnotetext{
${ }^{4}$ When the production function contains more than two factors, there are more than one measure of the elasticity of substitution between inputs. The AES (Allen, 1938, and Uzawa, 1962) is one of them and possibly the most popular. Far more important for our purposes is that it is the one used by Griliches (1969) to formalize the idea of the CSC hypothesis in a way consistent with Hicks factor substitution. The AES quantifies the percentage variation in the ratio of two inputs in response to a change in the ratio of the two input prices, holding all other prices (but not all other inputs) and the output quantity constant. Other measures of the elasticity of input substitution include, among others, the Hicks-Allen direct partial elasticity of substitution (Hicks and Allen, 1934a and 1934b) and the Morishima elasticity of substitution (Morishima, 1967).

${ }^{5}$ Most recent waves of the EU-KLEMS lack detailed labor information by skill type for the US. Besides, they do not dissagregate capital compensation into ICT and non-ICT, wich is used as extension.
} 
worked by college graduates as skilled, and aggregate middle and low skilled hours in a single category as unskilled.

Capital input in the EU KLEMS is defined in terms of capital services rather than stocks. Thus, capital is measured through its delivery of services in a year in terms of the user cost. The database provides capital service volume indexes at a given base year (1995). These indexes are constructed so that the total value of the services matches capital compensation, which is compatible with the assumption of constant returns to scale explicitly made in our translog specification. We compute the volume of capital services by multiplying the volume indices series by capital stock at the base year. ${ }^{6}$

Input prices required for estimating the system are computed by dividing compensations by their corresponding volume measure. Thus, skilled and unskilled wages are constructed by dividing the compensation of the particular labor type by the total number of hours worked provided in a year. Similarly, return to capital is obtained as the total capital compensation divided by the volume of capital services. In the translog system, prices can be normalized to one at a reference point (see, e.g., Ryan and Wales, 1998). Without loss of generality, we chose the base year 1995 as a reference point, which is also the reference year for the time trend that proxies the technology index.

Following Jorgenson and Timmer (2011), we aggregate the industries included in the original dataset to obtain a representative set of US market sectors that represent different patterns of growth and structural change. Non-market activities, such as public administration, education, and health, are not considered because they are not driven by the same efficiency considerations as market activities. The first sector considered is ICT-production, due to the importance of this sector in explaining economic growth (see, e.g., Jorgenson and Stiroh, 1999, Basu et al., 2004, and Byrne et al., 2013). ICT-production includes the manufacturing of electrical machinery and post and communication services; therefore, it combines products from the manufacturing and service industries. Other two sectors come from the rest of industries within goods production, which are divided between manufacturing (other than ICT) and

\footnotetext{
${ }^{6}$ The underlying idea in the construction of the database's indices is that the factor of proportionality between services and stocks does not remain constant over time but is one at the base year (see, e.g., Timmer et al., 2007).
} 
non-manufacturing goods; the latter includes agriculture, mining, utilities, and construction. The remaining three representative market sectors are the result of splitting services into financial and business services, distribution services, and personal services. Aggregated data from the previous six sectors defines t the market economy aggregation in the EU-KLEMS datase. Table 1 contains a complete definition of all the sectors considered.

As an extension, we also consider a set of two-sector splits of the market economy typically found in macroeconomic models. The data for the additional aggregations are not explicitly reported in the KLEMS database and have been constructed. We discuss this issue in the corresponding section (Section 6).

Figure 1 provides trends of the relative quantity of skilled hours, the skill premium, and the share of income earned by skilled labor relative to that of unskilled labor. At the aggregate level, our data present a typical result in the literature: both the relative quantity of skilled hours and the skill premium have grown significantly since 1980 . As a consequence, the skilled labor share of income relative to the unskilled have also grown strong. These findings are also reproduced in the different sectors, but with different magnitude. For instance, the relative supply of skilled hours in financial and business services is considerably larger than in the other sectors. The skill premium has widened more in services, especially in financial and business services and personal services. At the same time, ICT production and non-manufacturing goods present much more moderate skill premium patterns.

To illustrate the differences in the use of the inputs, Figure 2 depicts trends in the income shares of aggregate labor, skilled labor, and capital. These magnitudes were already analyzed in Jorgenson and Timmer (2011) for the same representative set sectors, so we refer to that work for a detailed description. Overall, we observe large disparities in the use of inputs across sectors that call for a sector-specific analysis of substitutability. Perhaps more interesting, the simultaneous increase in the use of skilled labor and capital in some sectors may signal complementarity between these two inputs. 


\subsection{Econometric framework}

We characterize the structure of technology in each sector by estimating the price function (3) jointly with the system of the factor cost-shares (4) subject to the restrictions derived from the theory of production. Although direct estimation of the price function can be achieved, the estimation of the share equations and the price function as a system improves efficiency, as it increases the degrees of freedom without requiring the estimation of additional parameters (Christensen and Greene, 1976).

To complete the stochastic model, we add to each of the equations a zero-mean disturbance term $\varepsilon_{i t}$, which can be understood as random errors in cost minimization. Given that the cost shares add to one, the system of the four share equations subject to the shocks $\varepsilon_{t}$ is over-determined. Following standard practice, we solve out the constraints of the shocks together with homogeneity by arbitrary dropping one of the equations of the system (the capital equation). The parameters from the dropped equation can be easily recovered from (5). Finally, we specify that the disturbance column vector is independently distributed with mean zero and a constant-singular variance-covariance matrix $\Omega$.

Input prices are determined by demand and supply and must be instrumented. We accounted for this potential concern and chose GMM 3SLS as our estimation procedure, which we iterate to reach invariance to the equation drop. In single country studies, the small number of data points makes the instrument selection a delicate issue since standard methods cannot properly test the exogeneity of the instruments. If any of the instruments is endogenous, the estimator become inconsistent.

As we focus on the market-side of the economy, we instrument input prices from all considered sectors with the corresponding prices of the public administration and defense sector. For the price function, we also employ as instruments the corresponding cross-products of this sector input prices. We supplement the instrument set of each equation with the working-age population, government capital stock, and the average marginal labor and effective corporate tax rates to have free moment conditions.

The key issue here is that the exogeneity of the instruments seems plausible. As it is usually assumed in macroeconomics, prices in the public sector, demographic, and 
fiscal variables are not responding (at least contemporaneously) to market prices. $^{7}$

Besides, a well-known result in the literature is that, in the absence of further restrictions, the concavity assumption is not satisfied in all sample points (Diewert and Wales, 1987). We usually find concavity violations in around $25 \%$ of the sample points in all estimations. As a consequence, concavity has to be enforced. While conditions (5) to (7) translate easily to restrictions on the estimated coefficients, the imposition of the concavity is slightly more complicated. As noted in expression (8), the assumption requires the Hessian to be negative semi-definite at all observed prices. Denoting the diagonal matrix with the shares in the main diagonal by $V_{t}=\operatorname{diag}\left(v_{t}\right)$, the concavity condition implies as well that the matrix

$$
B_{p p}-v_{t} v_{t}^{\prime}+V_{t}
$$

is also negative semi-definite. Although global concavity (at any possible point) can be easily imposed by decomposing the matrix of share elasticities $B_{p p}$ in terms of its Cholesky factorization, this procedure imposes unacceptable restrictions that drive out the flexibility of the translog. To circumvent this problem, we follow Gallant and Golub (1984) and Ruiz-Arranz (2002) and impose point-wise concavity at all sample points by means of constrained optimization.

Finally, given the small sample size, we do not make inference based on the asymptotic variance of the GMM 3SLS estimator but on moving block bootstrap (Künsch, 1989). The moving block bootstrap is robust to heteroskedasticity and autocorrelation of unknown forms. Gonçalves and White (2005) show that in the context of a multiple linear regression model with autocorrelated (and heteroscedastic) errors, confidence intervals that rely on moving block bootstrap tend to perform better than those that rely on the asymptotic closed-form variance. We chose a block size of three, based on Hall et al. (1995) rule of thumb, and simulate 500 replications of each estimated model, treating the system as a unit to conserve the variance structure across equations.

\footnotetext{
${ }^{7}$ As a robustness check, we reestimate all equations using lagged values of the instruments with no qualitative change in our results. The results are also robust to include (log) prices of the health and social work category as instruments of the first equation instead of using cross-products as instruments.
} 


\section{Estimation Results}

The estimation of the translog model provides coefficients that allow recovering the technical-change biases and, employing equation (8), the AES elasticities of substitution. Armed with these estimates, we can assess the empirical evidence on the SBTC and CSC hypothesis in our sample.

\subsection{Elasticities of substitution and the CSC hypothesis}

Table 2 presents the estimated (cross) AES calculated using average period shares. Given the sample size, the table reports bootstrapped standard errors in parenthesis. Recall that if $\sigma_{i j}^{A}>0$, an increase in the price of the $j$ th input raises the optimal quantity of input $i$, and inputs are substitutes. On the contrary, if $\sigma_{i j}^{A}<0$, the quantity of $i$ decreases, then the inputs $i$ and $j$ are complements.

At the aggregated level, skilled and unskilled labor are estimated substitutes in production. The relationship of the labor inputs with capital is different for each labor type. While unskilled labor and capital are also substitutes, the AES between skilled labor and capital is negative, which indicates complementarity. However, this elasticity is not statistically significant at two standard errors.

Patterns of input substitution across sectors for skilled and unskilled labor and unskilled labor and capital are similar to the patterns find at the aggregate level. In the two cases, the corresponding AES are positive and usually significant. There is more heterogeneity in the relationship between skilled labor and capital across sectors. In particular, a negative AES between these inputs is obtained in non-manufacturing goods and personal services. However, like at the aggregate level, this elasticity is non-significant at two bootstrapped standard errors. ${ }^{8}$

The CSC hypothesis only requires that capital and skilled labor are relatively more complementary as inputs than they are capital and unskilled labor. Put differently, as stated in inequality (11), CSC requires that the elasticity of substitution between capital and skilled labor is smaller than between capital and unskilled labor so that

\footnotetext{
${ }^{8} \mathrm{~A}$ further decomposition of the services into their primary forming industries generally gives consistent results. In particular, the AES across the industries that form a particular sector were quite similar, which indicates that the considered sectors are relatively homogenous. The exception is non-manufacturing goods, formed by very heterogeneous industries. These results are available upon request.
} 
the difference between these two elasticities is negative. The last column of Table 2 reports this difference. The table moves away from central confidence intervals and provides the $90 \%$ bootstrapped percentile bands to assess its statistical significance more accurately. Note that a $90 \%$ interval implies a significance level of $5 \%$ if the interval is employed for the testing of a one-sided hypothesis, such as CSC in (11) or SBTC in (9).

As Table 2 shows, the CSC finds strong support at the aggregate level. At the sectoral level, the support is smaller, being the CSC satisfied in half of the sectors. In particular, we find evidence of CSC in non-manufacturing goods, distribution, and personal services. Yet, for distribution services, the evidence is weak. For the remaining sectors, we find capital relatively more complementary to unskilled labor. Importantly, while the evidence across sectors is mixed, the elasticities between labor groups and capital are significant only in sectors where the CSC holds, especially personal services where it shows up super strong. These facts can explain the support of CSC at the aggregate level.

As a last check, we also evaluate the CSC hypothesis computing the AES at two selected sample points (1975 and 2000) instead of using average period shares. Assessing the CSC at different sample points is important because the cost shares of the skilled labor and capital have been rising steadily between 1970 to 2005, as shown in Figure 2. We find a decline over time in the magnitude of the elasticity between capital and skilled labor pointed out in other studies (see, e.g., Ruiz-Arranz, 2002). This decline can be easily explained by the increases in both capital and skill labor shares of income. ${ }^{9}$ However, our findings are qualitatively identical to those reported in Table 2, and not reported here to save space, although they are available upon request to the authors.

\subsection{Factor non-neutral technological change}

The estimated biases of technical change are provided in Table 3. Columns one and two show the bias for skilled and unskilled labor, respectively, along with the bootstrap standard errors in parenthesis. Technological change is found unskilled saving both at

\footnotetext{
${ }^{9}$ Note that the AES between capital and skilled labor can be rewritten as $\sigma_{S K}^{A}=1+\left(\beta_{S K} / v_{s} v_{k}\right)$, falling both with capital and skilled labor shares of income.
} 
the aggregate level and for the different sectors . At the same time, column one says that technology advances have augmented the relative share of skilled labor. Moving now to the capital assets, column three shows that technical progress is capital using.

Therefore, our estimation results suggest that technological change has increased the share of skilled workers and reduced that of unskilled. Recall from expression (9) that SBTC is satisfied if the bias of technical change for skilled labor is larger than the one of the unskilled. In terms of the estimated parameters, this implies that $\beta_{S T}-\beta_{U T}$ (given by the fourth column of Table 3) is larger than zero. To check for the statistical significance, the last two columns of the table provide the $90 \%$ bootstrapped confidence intervals. We can see that the SBTC hypothesis receives strong statistical support.

\subsection{Factors behind the observed changes in the skill premium}

The results of the previous sections provide supporting evidence for both the CSC and SBTC hypothesis at the aggregated level and in many sectors. It is, therefore, necessary to gauge their relative importance in explaining the observed patterns in the data. We decompose the growth rates of the skill premium into the contribution attributed to the growth of each different input and each of the different biases. This implies an alternative definition of the CSC in terms of quantities instead of the prices. That is to say, we ask by which amount the observed increase in the volume of capital services during the period 1970-2005 (probably induced by the observed decline in its price) has raised the relative price of skilled labor.

Following Ruiz-Arranz (2002), the yearly growth rate of the skill premium predicted by the model is split into three components: a labor quantity effect, a capital quantity effect, and a technology effect (see the mathematical appendix at the end of this work for details):

$$
g_{S P}=\underbrace{\left(\phi_{1} g_{S}+\phi_{2} g_{U}\right)}_{\text {Labor quantity effect }}+\underbrace{\left(\phi_{3} g_{K}\right)}_{\text {Capital quantity effect }}+\underbrace{\left(\varphi_{1} \beta_{S T}+\varphi_{2} \beta_{U T}+\varphi_{3} \beta_{K T}\right)}_{\text {Technology effect }} ;
$$

where $g_{k}$ denotes the growth rate in the supply of input $k$.

The labor quantity effect captures the impact of changes in the quantities of the two labor inputs on the skill premium. Given the observed trends in the relative supply of 
skilled labor and the sign of the estimated elasticities between the two labor inputs, we expect this contribution to be mostly negative. Similarly, the capital quantity effect collects the impact of the growth rates of the two capital inputs. If the CSC hypothesis is important at explaining the observed pattern in the wage premium, we expect the capital quantity effect to be positive and large. Finally, the last term in equation (13) is the technology effect, which measures the impact of all input biases of technological change. More specifically, the term $\varphi_{1} \beta_{S T}+\varphi_{2} \beta_{U T}$ captures the influence of the labor input bias (labor technology effect); whereas the term $\varphi_{3} \beta_{K T}$ gathers the effect of the capital input bias (capital technology effect). Therefore, if controlling for potential complementarities, the SBTC is the major force behind the rise in the skill premium, the technology effect should be positive and relatively large.

For each sector, we feed equation (13) with the parameters from the estimated cost share equations and employ the yearly growth rates of input quantities to obtain the model prediction of the yearly growth rate of the skill premium. We cumulate model predictions over the 1980-2005 time interval, which is the period where the premium rises (see Figure 1). The result is presented in the penultimate column of Table 4 (column five), and measures the percentage change over the entire period predicted by the model. The actual percentage change in the data is provided in the last column of Table 4 (column six).

As can be observed in the table, the translog model does a good job predicting the yearly growth rate of the skill premium. As a result, the implied cumulated change over the entire period is usually close to the observed change in the data.

In columns one to seven of Table 4, we broke down the change predicted in the model into the components discussed above: a labor quantity effect, a capital quantity effect, and a factor non-neutral technology effect. The first result that stands out is contained in column one. In the absence of any compensation mechanism, the skill premium would have fallen dramatically as a consequence of the observed trend in skilled labor. Since we do not observe this strong fall, the labor quantity effect must have been compensated by changes in the volume of capital services or by technical change (or both).

The capital quantity effect (second column of Table 4) usually has the expected sign, increasing the skill premium at the aggregate level and in the sectors and industries 
where the CSC holds. ${ }^{10}$ The magnitude at the aggregate level is large, although not enough to compensate for the labor quantity effect. The capital quantity effect is generally less important across sectors than at the aggregate level, although often contributes decisively to the observed growth in the skill premium as well. However, consistent with the estimated AES elasticities, the increase in the volume of capital services has greatly reduced the skill premium in financial and business services and ICT production.

Finally, columns three and four of Table 4 show that the technical change effect, split down into its two components, labor technology effect and capital technology effect. As the table shows, the non-neutral technological change always contributes to the positive evolution of the wage skill premium. Comparing columns five and six, note that the positive impact comes from the labor-technology effect, that is, mainly as a consequence of skill-biased technology advances, as the capital technology effect is often negative.

Overall, comparing the different effects, our estimates suggest that both CSC and SBTC are equally important in explaining the premium growth at the aggregate level. This result, however, does not hold in all sectors, being the labor technology effect usually larger, being the SBTC the most important driver of the skill premium growth. Yet, in non-manufacturing goods and personal services, the capital quantity effect dominates, suggesting that CSC is more important than SBTC in explaining the patterns in the data in some specific sectors. Our results also point towards that the importance of CSC raises with the level of aggregation. We explore this issue in Section (6).

\subsection{Factors behind the observed change in the skilled labor share of income relative to the unskilled}

the simultaneous increase in both the relative quantity of skilled labor and the skill premium has led to a substantial rise in the share of skilled labor on income relative to the unskilled. The estimated translog model can also be employed to gauge the

\footnotetext{
${ }^{10}$ A positive capital quantity effect is not guaranteed by a negative difference in the AES in Table 2. The numbers in this table are constructed employing average period shares, while results in Table 4 are based on AES computed from yearly shares. Also, the capital quantity effect is not necessarily positive unless skilled labor and capital are estimated complements that year while, at the same time, the unskilled labor and capital are estimated substitutes.
} 
relative importance of the CSC and SBTC hypothesis on the observed changes in this magnitude. As with the skill premium, we can disaggregate the yearly growth rate of the relative skilled labor intensity $\left(g_{r v}\right)$ as (see the mathematical appendix):

$$
g_{r v}=\underbrace{\left(\theta_{1} g_{S}+\theta_{2} g_{U}\right)}_{\text {Labor quantity effect }}+\underbrace{\left(\theta_{3} g_{K}\right)}_{\text {Capital quantity effect }}+\underbrace{\left(\gamma_{1} \beta_{S T}+\gamma_{2} \beta_{U T}+\gamma_{3} \beta_{K T}\right)}_{\text {Technology effect }} .
$$

Once more, we can plug the estimated translog parameters into the last expression together with the observed yearly growth rates of input quantities to obtain a model prediction of the yearly growth rate of the relative share of skilled labor. The last two columns of Table 5 summarize the percentage change of the relative skilled labor intensity during the observed period implied by the model predictions and by the data. As before, we have broken down the predicted change between 1980 and 2005 into the contribution of the labor quantity (column two), capital quantity (column three), and non-neutral technology (columns four and five) effects. The numbers in the table make evident the large increases in this magnitude that have taken place during the observed period in all sectors and industries. The translog model tracks the changes well, as the total change predicted by the model is similar to the actual change in the data.

The supply of capital and non-neutral technical change has the same contribution reported in Table 4, as their contribution to the relative skilled labor intensity comes through their effect on the relative wage. Consequently, the interest here is the labor quantity effect. Notice that its sign is a priori undetermined. On the one hand, the rise in the relative quantity of skilled labor increases the relative share of the skilled. On the other, the negative effect that this additional amount of skilled has in the relative wage makes the relative share of the skilled going down. For the market economy, as well as for personal services, the second effect dominates, and the total labor quantity effect is negative. We can also find a negative quantity effect in several industries, such as investment manufacturing, all industries from the personal services sector, and construction.

\section{Extensions}

We extend the baseline analysis above along two different directions. First, we assess CSC and SBTC across several two-sector splits of the market economy common in the 
macroeconomic literature. After, we consider a four input translog specification, where we treat ICT and non-ICT capital as different inputs.

\subsection{Extension I: two-sector splits}

In addition to the classification that combines the original industries into six market sectors, we also divide the market economy into different sets of aggregates that follow criteria typically employed in macroeconomic models. The purpose here is offering useful information to these models about certain features of the production function, such as the elasticity of input substitution and the relative importance of input-biased technological change. More specifically, following Valentinyi and Herrendorf (2008), we consider (i) agriculture versus non-agriculture; (ii) tradable versus non-tradable products; and (iii) investment goods versus consumption products. The analysis would also help to study whether the importance of the CSC increases with the level of aggregation, as our previous results suggest. Table 1 contains a precise definition of the different two-sector splits.

Unlike data for the representative set of sectors, data for the two-sector splits is not explicitly reported in the EU KLEMS dataset and need to be constructed. Input compensations and hours worked for each type of labor are computed as the sum across the industries employed to form the aggregate. The volume of capital services provided is also constructed proportionally to the stocks of capital in the base year.

In the construction of the investment-consumption aggregates, similarly to Valentinyi and Herrendorf (2008), a fraction of intermediate manufacturing and services are assigned to investment. This fraction is computed from the WIOD (World Input-Output Database), September 2012 release. ${ }^{11}$ We take into account that each industry offers data on its contribution to gross capital formation and to intermediate consumption, and that a fraction of intermediate consumption is devoted to investment. Hence, the fraction of the industry gross value added that we attribute to investment - which is the one that we employ to split inputs and compensations - equals its direct contribution to gross capital formation plus its indirect contribution through intermediate

\footnotetext{
${ }^{11}$ WIOD reports data for 35 sectors classified according to ISIC (United-Nations International Standard Industrial Classification of Economic Activities), review 3, and covers the period 1995-2011; see Timmer et al. (2015) for details. In the construction of the investment aggregate, we apply the percentages computed for 1995 to all years between 1970 and 1995.
} 
consumption, everything divided by the total sector use net of exports. The indirect contribution to investment through intermediate consumption, in turn, equals intermediate consumption times the share of intermediate consumption devoted to investment, being this last share equal to the proportion attributed to investment from intermediate manufacturing products, which is solved iteratively. Given the strong assumptions involved in the construction of the investment and consumption aggregates, results from this aggregation must be taken with caution.

Results for the three sets of splits are reported in the second block of Tables 2, 3, 4, and 5. As Table 2 shows, the estimated AES between skilled and unskilled labor and between unskilled labor and capital are positive in all splits. This implies that the substitution between these inputs is robust to aggregations. The AES between capital and skilled labor is usually negative, but statistically non-significant, just like at the aggregate level. Still, the evidence of CSC is always strong except for agriculture. As for the SBTC, we also find the same results than in our baseline estimations. Technical advances increase the shares of the skilled labor and capital, and decreases that of unskilled labor.

We employ the same decompositions in Sections 5.3 and 5.4 to gauge the relative importance of CSC and SBTC. Both CSC and SBTC appear to be important in explaining the patterns in the data. Only in agriculture, the increase in the skill premium, which is smaller than in the other aggregates, is explained by SBTC alone, as the capital quantity effect is negative in this aggregation. The effect of labor quantity on the relative share of skilled labor is negative in all aggregation pairs, like with completely aggregated data.

Overall, the results using the two sample splits are stronger than across the main sectors considered, very similar than the ones obtained at the aggregate level, and confirm previous evidence that CSC increases in importance with the level of aggregation of the data.

\subsection{Extension II: translog specification with four inputs}

As a second extension, we consider a four input translog specification, where we treat ICT and non-ICT capital as different inputs. The distinction between ICT and nonICT capital might be important because the former has been accumulating at a faster 
rate, which has made several authors consider this capital type the principal source of CSC (see, e.g., Krusell et al., 2000).

We have not considered disaggregated capital data as our benchmark because the return to ICT services computed from the EU-KLEMS data presents unappealing fluctuations during the 70's that can bias our estimations. Problems with disaggregated data during the 70's are well-known, as those years were a noisy and volatile period. ${ }^{12}$ Consequently,we present the results of the translog specification with four inputs here as an extension. However, the results must be taken with some caution.

The estimated AES for the aggregated market economy and the six principal sectors are presented in Table 6. Skilled and unskilled labor are once more estimated substitutes, both at the market level and across sectors. ICT and non-ICT capital are also substitutes except in non-manufacturing goods, where the AES is negative, yet not significant at two bootstrapped standard errors.

The interest here lies, however, in the relationship between labor and the two capital types. For the aggregated market economy, ICT and non-ICT are complements with skilled labor but substitutes with unskilled.

There is more heterogeneity at the sector level, although skilled labor and capital (both ICT and non-ICT) are estimated complements more often than capital and unskilled. Yet, the evidence of direct complementarities between any labor and capital type is most often statistically weak.

The last two columns of Table 6 present the estimated difference between the elasticities of the two labor inputs with each capital type. Recall that a negative difference indicates CSC. As in the baseline specification, we include bootstrapped $90^{\text {th }}$ percentile bands to judge on its statistical significance. Consistent with the estimated AES, we find strong evidence of CSC using aggregate data, and skilled labor is more complementary to ICT and non-ICT capital than is unskilled labor.

At lower levels of aggregation, the evidence of CSC is mixed, depending on the particular sector and capital type. In general, we find broader and more robust evidence of CSC originated in non-ICT capital. The non-ICT-CSC hypothesis is satisfied in all sectors, except manufacturing goods and financial and business services, and is

\footnotetext{
${ }^{12}$ We thank the referee for pointing this out. Besides, ICT accounts in the 70's just for a small share of total capital compensations and volume.
} 
generally significant. There is support for the ICT-CSC in many sectors as well, but the evidence at $5 \%$ significance can only be established for financial and business services.

Table 7 present the estimated bias of technical change in the four-input model. As can be observed in the table, the results follow those of the baseline model. Technical change is skilled-labor using and unskilled-labor saving. Evidence of SBTC is significant in all sectors. Concerning the capital biases, the estimates are also positive and present similar magnitudes, indicating that progress is not favoring any particular capital type over the other.

To assess the relative importance of (ICT and non-ICT) CSC and SBTC, we quantify the effect of each input quantity and each input bias in the yearly growth rates of the skilled premium and the relative share of skilled labor predicted by the model, just as we do in the baseline specification:

$$
g_{S P}=\underbrace{\left(\phi_{1} g_{S}+\phi_{2} g_{U}\right)}_{\text {Labor quantity effect }}+\underbrace{\left(\phi_{3} g_{I}+\phi_{4} g_{N}\right)}_{\text {Capital quantity effect }}+\underbrace{\left(\varphi_{1} \beta_{S T}+\varphi_{2} \beta_{U T}+\varphi_{3} \beta_{I T}+\varphi_{4} \beta_{N T}\right)}_{\text {Technology effect }} ;
$$

and

$$
g_{r v}=\underbrace{\left(\theta_{1} g_{S}+\theta_{2} g_{U}\right)}_{\text {Labor quantity effect }}+\underbrace{\left(\theta_{3} g_{I}+\theta_{4} g_{N}\right)}_{\text {Capital quantity effect }}+\underbrace{\left(\gamma_{1} \beta_{S T}+\gamma_{2} \beta_{U T}+\gamma_{3} \beta_{I T}+\gamma_{4} \beta_{N T}\right)}_{\text {Technology effect }} ;
$$

where the sub-indices $I$ and $N$ denote ICT and non-ICT capital, respectively.

The percentage change in the skill premium over the 1980-2005 time-interval, together with the decomposition in the labor quantity, capital quantity, and technology effects, is presented in Table 8. In the last two columns, this table shows that the four-input specification also predicts the data well. The labor quantity effect (column one) is always negative and strong, consistent with the baseline results.

We split the capital quantity effect into the contribution of ICT (column two) and non-ICT (column three) capital. Concerning non-ICT capital, its effect on the skill premium is positive, both at the aggregate level and across sectors. Furthermore, the magnitude is often relatively large, explaining a considerable part of the skill premium change. The exception is manufacturing, where the effect is negative, although very small in magnitude. The ICT capital quantity effect also has the expected sign, contributing positively to the skill premium there where the ICT-CSC holds. This effect is huge in financial and business services. Therefore, disaggregation of capital into 
ICT and non-ICT is crucial to assess CSC in this sector, as we do not find evidence of CSC in the baseline estimation. A possible explanation is that the financial and business services sector has experienced the largest growth in the ICT capital share of income among all considered sectors, but a relatively small growth in the aggregate capital share. The ICT quantity effect is also positive and large in personal services, although to a considerably lower extent, but lowers the skill premium in manufacturing, distribution, and, especially, ICT production.

Finally, columns four and five of Table 8 gather the aggregate effect of the two labor biases and the two capital biases. Consistent with the previous results, the combined effect of the two labor biases (labor technology effect) is always positive and strong, except for financial and business services. Interestingly, the aggregated effect of the two capital biases often contributes to the premium negatively, as we find in the baseline estimations.

As for the factors explaining the growth in the skilled labor share of income relative to the unskilled, the (ICT and non-ICT) capital and technical change effects follow those in Table 8, because their impact comes through the relative wage only. Theoretically, as noted before, the aggregated labor quantity effect is uncertain, as the observed increase in the relative quantity of skilled labor impacts positively through relative quantities but negatively through the skilled premium. As Table 9 shows, the overall estimated effect is generally positive.

Overall, the results of the four input specification highlight once more that both CSC and SBTC contribute to the observed increase in the relative wage of skilled labor. At the aggregate level, the contribution of CSC and SBTC to the growth of the skill premium is very similar. Across sectors, the contribution of SBTC is usually larger, but CSC is also an important driver of the premium. Contrary to what we expected, we find that the primary source of CSC is often non-ICT capital. Yet, complementarities arising in ICT contribute decisively to the skill premium growth in some sectors, especially in financial and business services. The exception is ICTproduction, where SBTC accounts for all the observed growth and seems to have reduced the skill premium through the accumulation of (ICT) capital. A possible explanation is the temporary nature of the CSC defended by Goldin and Katz (1998), Caselli (1999), and Galor and Moav (2000). They suggest that the CSC is more likely 
to exist during the technological transition, but once this transition is completed, the endogenous outcome may deviate from CSC. The ICT-production sector may have completed earlier the digital revolution, and there is no particular reason to expect that (ICT) capital must be more complementary to skilled workers during most of the observed sample.

\section{Conclusion}

In this work, we have reexamined the evidence on the CSC and SBTC hypotheses using sectoral data for the US economy from 1970 to 2005. We find overwhelming evidence that technological progress has been non-neutral, rising the relative productivity of skilled workers over unskilled in all considered sectors and aggregations. However, we also find strong support for the CSC at the aggregate level and in many sectors. The assessment of the relative contribution of these two phenomena to the observed changes in the skill premium has revealed that both CSC and SBTC are important in explaining the observed changes in the premium, especially using data at higher levels of aggregation. At a more disaggregated level, the contribution of SBTC to the skill premium growth is often larger, although CSC also contributes decisively to the skill premium growth in many sectors. Our analysis has also revealed that the evidence of CSC arising in non-ICT capital is wider and usually more robust. However, complementarities originated in ICT capital are essential to explain the skill premium patterns in some sectors, especially in financial and business services.

As any applied work, this study is subject to many drawbacks and limitations. In our view, the most critical is the limited time span of the data, which may penalize the efficiency of estimations. As suggested by a referee, we have also estimated the translog system with a panel of OECD economies using data from the same EU KLEMS database. We find that imposing the sector's technology to be the same for all countries in all periods is far too restrictive, even assuming fixed effects. As a result, the estimated translog system fits the data poorly and, more importantly, does an awful job predicting the skill premium changes across countries. In fact, the skill premium has evolved differently in the OECD countries, possibly due to their different labor market institutions (see, e.g., Koeninger et al., 2007). Future research should contribute to 
disentangling these differences across countries in the evolution in the skill premium.

We have left out as well other issues of interest. For example, if CSC is just a transitory phenomenon arising during technological revolutions, as argued in Goldin and Katz (1998), Caselli (1999), and Galor and Moav (2000), the degree of maturity in the use of capital may explain why we find CSC in some sectors but not in others. Consequently, it would be interesting to study if some of the translog parameters driving the value of the elasticities of substitution have changed at some point in time. The existence of nonlinearity would be consistent with the evidence reported in Goldin and Katz (1989) or Papageorgiou and Chmelarova (2005). Unfortunately, we have too few observations to detect structural breaks reliably.

Our work also omits other factors, such as trade, which might have also contributed to the observed rise in the skill premium. In a standard Heckscher-Ohlin model, the Stolper-Samuelson theorem ensures that the relative wage of skilled workers goes up when the relatively skill abundant country engages in trade. We do no find significant differences in the contributions of the different factors to the changes in the skill premium between the tradables and non-tradables aggregations. However, these differences exist at a more disaggregated level, implying that trade may still play a significant role, as found in Feenstra (1996). Besides, trade affects the skill premium in other ways than the pure Heckscher-Ohlin mechanism (Acemoglu, 2003).

Finally, a related debate, which also requires disaggregated analysis, revolves around whether the ongoing introduction of "robots" is eroding labor markets (see, e.g., DeCannio, 2016; Acemoglu and Restreppo, 2019). Data on robot penetration by sector or industry is required to address this interesting question. Overall, we find all these issues exciting avenues for further research. 


\section{References}

[1] Acemoglu D (2002) Technical change, inequality, and the labor market. Journal of Economic Literature 40: 7-72.

[2] Acemoglu, D (2003) Patterns of Skill Premia. Review of Economic Studies 70:199230 .

[3] Acemoglu D, Restrepo (2019) Automation and New Tasks: How Technology Displaces and Reinstates Labor. Journal of Economic Perspectives 33: 3-30.

[4] Allen RGD (1938) Mathematical Analysis for Economists. London, Macmillan.

[5] Antras P (2004) Is the U.S. aggregate production function Cobb-Douglas? New estimates of the elasticity of substitution. Contributions in Macroeconomics 4: 1534-6005.

[6] Balleer A, van Rens T (2013) Skill-biased technological change and the business cycle. Review of Economics and Statistics 95: 1222-1237.

[7] Basu S, Fernald JG, Oulton N, Srinivasan S (2004) The case of the missing productivity growth, or does information technology explain why productivity accelerated in the United States But Not in the United Kingdom?" NBER Macroeconomics Annual 2003.

[8] Bergstrom V, Panas EE (1992) How robust is the capital-skill complementarity hypothesis? Review of Economics and Statistics 74: 540-546.

[9] Berman E, Bound J, Griliches Z (1994) Changes in the demand for skilled labor within U.S. manufacturing: Evidence from the annual survey of manufacturers. Quarterly Journal of Economics 109: 367-397.

[10] Berndt ER, Christensen LR (1973) The translog function and the substitution of equipment, structures, and labor in U.S. manufacturing 1929-68. Journal of Econometrics 1: 81-113.

[11] Betts JR (1997) The skill bias of technological change in Canadian manufacturing industries. The Review of Economics and Statistics 79: 146-150.

[12] Bound J, Johnson G (1992) Changes in the structure of wages during the 1980s: an evaluation of alternative explanations. American Economic Review 82: 371-392.

[13] Berndt ER, Wood D (1975) Technology, prices, and the derived demand for energy. The Review of Economics and Statistics 57: 259-268.

[14] Binswanger HP (1974) A Cost Function Approach to the Measurement of Elasticities of Factor Demand and Elasticities of Substitution. American Journal of Agricultural Economics 56: 377-386.

[15] Burnside C, Eichenbaum M (1996) Small sample properties of GMM based Wald tests. Journal of Business and Economic Statistics 14: 294-308.

[16] Byrne DM, Oliner SD, Sichel DE (2013) Is the information technology revolution over? Finance and Economics Discussion Series Working Paper. Federal Reserve Board. 
[17] Caselli F (1999) Technological revolutions. American Economic Review 89: 78102.

[18] Christensen LR, Jorgenson DW, Lau LJ (1973) Transcendental logarithmic production frontiers. Review of Economics and Statistics 55: 28-45.

[19] Christensen, LR,Greene, WH (1976) Economies of Scale in U.S. Electric Power Generation. Journal of Political Economy 84: 655-676.

[20] Chun H (2003) Information technology and the demand for educated workers: disentangling the impacts of adoption versus use. Review of Economics and Statistics 85: $1-8$.

[21] DeCanio SJ (2016) Robots and humans - complements or substitutes? Journal of Macroeconomics 49: 280-291.

[22] Dhrymes PJ (1994) Specification tests in simultaneous equation systems. Journal of Econometrics 64: 45-76.

[23] Diewert WE, Wales TJ (1987) Flexible functional forms and global curvature conditions. Econometrica 55: 43-68

[24] Duffy J, Papageorgiou C, Perez-Sebastian F (2004) Capital-skill complementarity? evidence from a panel of countries. Review of Economics and Statistics 86: 327344 .

[25] Efron B (1987) Better bootstrap confidence intervals. Journal of the American Statistical Association 82: 171-185.

[26] Fallon PR, Layard R (1975) Capital-skill complementarity, income distribution, and output accounting. Journal of Political Economy 83: 279-302.

[27] Feng G, Serletis A (2008) Productivity trends in U.S. manufacturing: Evidence from the NQ and AIM cost functions. Journal of Econometrics 142: 281-311.

[28] Feenstra, RC (1996) Trade and uneven growth. Journal of Development Economics 49: 229-256.

[29] Gallant AR, Golub G (1984) Imposing curvature restrictions on flexible functional forms. Journal of Econometrics 26: 295-321.

[30] Galor O, Moav O (2000) Ability-biased technological transition, wage inequality within and across groups, and economic growth. Quarterly Journal of Economics 115: 469-97.

[31] Goldin C, Katz LF (1998) The origins of technology-skill complementarity. Quarterly Journal of Economics 113: 693-732.

[32] Gonçalves S, White H (2005) Bootstrap Standard Error Estimates for Linear Regression. Journal of the American Statistical Association 100: 970-979.

[33] Griliches Z (1969) Capital-skill complementarity. Review of Economics and Statistics 5: 465-68.

[34] Hall P, Horowitz JL, Jing BY (1995). On blocking rules for the boostrap with dependent data. Biometrika 82: 561-574. 
[35] Herrendorf B, Herrington C, Valentinyi A (2015) Sectoral technology and structural transformation. American Economic Journal: Macroeconomics 7: 104-133.

[36] Hicks JR, Allen RGD (1934a) A reconsideration of the theory of value, part I. Economica 1: 52-76.

[37] Hicks JR, Allen RGD (1934b) A reconsideration of the theory of value, part II. Economica 1: 196-219.

[38] Jin H, Jorgenson DW (2010) Econometric modeling of technical change. Journal of Econometrics 157: 205-219.

[39] Jorgenson DW, Gollop FM, Fraumeni BM (1987) Productivity and US economic growth, Harvard University Press, Cambridge, MA.

[40] Jorgenson DW, Stiroh KJ (2000) Raising the speed limit: U.S. economic growth in the information age. Brookings Papers on Economic Activity 31: 125-236.

[41] Jorgenson DW, Timmer MP (2011) Structural change in advanced nations: a new set of stylized facts. Scandinavian Journal of Economics 113: 1-29.

[42] Karabarbounis L, Neiman B (2013). The global decline of the labor share. The Quarterly Journal of Economics 129: 61-103.

[43] Katz L, Murphy K (1992) Changes in relative wages: utility and demand factors. Quarterly Journal of Economics 107: 35-78.

[44] Koeniger W, Leonardi M, Nunziata N (2007). Labor Market Institutions and Wage Inequality. ILR Review 60: 340-356.

[45] Krusell P, Ohanian L, Rios-Rull V, Violante G (2000) Capital-skill complementarity and inequality. Econometrica 68: 1029-1053.

[46] Künsch HR (1989) The jacknife and the bootstrap for general stationary observations. The Annals of Statistics 17: 1217-1241.

[47] Morishima M (1967) A few suggestions on the theory of elasticity (in Japanese). Keizai Hyoron (Economic Review) 16, 144-150.

[48] O’Mahony M, Timmer MP (2009) Output, input, and productivity measures at the industry level: the EU KLEMS database. Economic Journal 119: 374-403.

[49] Papageorgiou C, Chmelarova V (2005) Nonlinearities in capital-skill complementarity. Journal of Economic Growth 10: 59-89.

[50] Ryan D., Wales TJ (1998) A Simple Method for Imposing Local Curvature in Some Flexible Consumer-Demand Systems. Journal of Business and Economic Statistics 16: 331-338.

[51] Richter B (2013) Essays on the skill premium and the skill bias of technological change. PhD Thesis, London School of Economics.

[52] Ruiz-Arranz M (2002) Wage inequality in the US: capital-skill complementarity vs skill-biased technical change. Mimeo, Harvard University. 
[53] Sato K (1967) A two-level constant-elasticity-of-substitution production function. Review of Economic Studies 34: 201-218.

[54] Stokey NL (1996) Free trade, factor returns, and factor accumulation. Journal of Economic Growth 1: 421-4.

[55] Timmer MP, O’Mahony M, van Ark M (2007) EU KLEMS Growth and Productivity Accounts: An Overview. International Productivity Monitor, Centre for the Study of Living Standards, vol. 14: 71-85.

[56] Timmer MP, Inklaar R, O'Mahony M, van Ark B (2011). Productivity and Economic Growth in Europe: A Comparative Industry Perspective. International Productivity Monitor, Centre for the Study of Living Standards, 21:3-23.

[57] Timmer MP, Dietzenbacher E, Los B, Stehrer R, de Vries GJ (2015) An illustrated user guide to the World Input-Output Database: the case of global automotive production. Review of International Economics 23: 575-605.

[58] Uzawa H (1962) Production functions with constant elasticities of substitution. Review of Economic Studies 29: 291-299.

[59] Valentinyi A, Herrendorf B (2008) Measuring factor income shares at the sectoral level. Review of Economic Dynamics 11: 820-835. 


\section{Mathematical Appendix}

In this appendix, we first show how to decompose the growth rates of the skill wage premium and the relative share of skilled labor. After this, we discuss how to impose concavity restrictions. The discussion closely follows Ruiz-Arranz (2002). We refer to this work for further explanations.

\subsection{Decomposition of the growth rates of the skilled premium and the relative share of skilled}

In order to decompose the growth of the skill premium, we apply the Shephard's lemma and write the input quantities as:

$$
q=\frac{\partial P Q}{\partial p}=\frac{\partial P}{\partial p} Q+\frac{\partial Q}{\partial p} P=\frac{\partial \ln P}{\partial \ln p} \frac{P}{p} Q=v \frac{P Q}{p}
$$

where we have suppressed time and sector indices for simplicity. The vector $q$ contains the input quantities, $p$ is a vector of input prices, and $\nu$ is the vector of cost shares. The variables $P$ and $Q$ denote the output price and quantity, respectively.

From equation (17), we can express the vector of input prices as: $p=\nu P Q / q$. Log-differencing this last equality with respect to time results in $g_{p}=g_{\nu}-g_{q}+g_{P Q}$, where $g_{x}$ is the growth rate of a variable $x$. From expression (4) in the text, we can rewrite the growth rate of the cost shares as $g_{\nu}=\Lambda\left(B_{p p} g_{p}+\beta_{p T}\right)$, where $\Lambda$ is a diagonal matrix containing the inverse of cost shares in the main diagonal. Combining the last two equalities obtains:

$$
g_{p}=\left(\Lambda B_{p p}-I\right)^{-1}\left(g_{q}-\Lambda \beta_{p T}-g_{P Q}\right) .
$$

Thus, we can express the growth rate of the skill premium as in equation (13), that is,

$$
g_{S P}=\left(\phi_{1} g_{S}+\phi_{2} g_{U}\right)+\left(\phi_{3} g_{K}\right)+\left(\varphi_{1} \beta_{S T}+\varphi_{2} \beta_{U T}+\varphi_{3} \beta_{K T}\right)
$$

where the parameter $\phi_{i}$ is the element $(1, i)$ minus the element $(2, i)$ of the matrix $\left(\Lambda B_{p p}-I\right)^{-1}$, and $\varphi_{i}$ is the difference between the elements $(1, i)$ minus the element $(2, i)$ of the matrix $-\left(\Lambda B_{p p}-I\right)^{-1} \Lambda$.

We decompose the growth of the relative share of skilled labor in a similar way. Using the equality $p=\nu P Q / q$ inside equation (4), the vector of input shares can be rewritten as

$$
\nu_{t}=\alpha_{p}+B_{p p} \ln \left(\nu \frac{P Q}{q}\right)+\beta_{p T} t .
$$

Differentiating with respect to time leads to: $g_{\nu}=\Lambda\left[B_{p p}\left(g_{\nu}-g_{q}+g_{P Q}\right)+\beta_{p T}\right]$; where, as before, $\Lambda$ is a diagonal matrix containing the inverse of cost shares in the main diagonal. Since $B_{p p} g_{P Q}=0$, we can arrange the previous expression as

$$
g_{v}=\left(B_{p p}-\Lambda^{-1}\right)^{-1}\left(B_{p p} g_{q}-\beta_{p T}\right)
$$

Thus, the growth rate of the relative share of skilled labor can be decomposed as in equation (14), that is,

$$
g_{r v}=\left(\theta_{1} g_{S}+\theta_{2} g_{U}\right)+\left(\theta_{3} g_{K}\right)+\left(\gamma_{1} \beta_{S T}+\gamma_{2} \beta_{U T}+\gamma_{3} \beta_{K T}\right)
$$

where $\theta_{i}$ and $\gamma_{i}$ are the differences between the elements $(1, i)$ and $(2, i)$ of the matrices $\left(B_{p p}-\Lambda^{-1}\right)^{-1} B_{p p}$ and $-\left(B_{p p}-\Lambda^{-1}\right)^{-1}$, respectively. 


\subsection{Imposing concavity restrictions}

We enforce concavity by means of constrained optimization. As noted in equation (8), the concavity condition requires the matrix

$$
\Theta_{t}=B_{p p}-v_{t} v_{t}^{\prime}+V_{t}
$$

to be non-positive definite at each period observed cost shares. To impose this constraint, we fist decompose in terms of its Cholesky decomposition $\Theta_{t}=L D L$ where

$$
L_{t}=\left(\begin{array}{ccc}
1 & & \\
l_{21} & 1 & \\
l_{31} & l_{32} & 1
\end{array}\right) ; D_{t}=\left(\begin{array}{lll}
d_{1} & & \\
& d_{2} & \\
& & d_{3}
\end{array}\right)
$$

Identifying these terms (and supressing time indices) leads to:

$$
\begin{aligned}
d_{1} & =\beta_{11}+v_{1}^{2}-v_{1} \\
l_{12} & =\left(\beta_{12}+v_{1} v_{2}\right) / d_{1} \\
d_{2} & =\beta_{22}+v_{2}^{2}-v_{2}-d_{1} l_{12}^{2} \\
l_{13} & =\left(\beta_{13}+v_{1} v_{3}\right) / d_{1} \\
l_{23} & =\left(\beta_{23}+v_{2} v_{3}-d_{1} l_{12} l_{13}\right) / d_{2} \\
d_{3} & =\beta_{33}+v_{3}^{2}-v_{3}-d_{1} l_{13}^{2}-d_{2} l_{23}^{2} ;
\end{aligned}
$$

where simmetry, linear homogeity, and product exaustion imply that $d_{3}=0$. 


\section{TABLES AND FIGURES}

TAB. 1-DESCRIPTION OF ALL SECTORS AND AGGREGATIONS

\begin{tabular}{|c|c|c|}
\hline & Abbrev. & NACE1 \\
\hline Market Economy & MARKT & ELECOM + MEXELEC + OTHERG + FINBU + DIST + PERS \\
\hline \multicolumn{3}{|c|}{ PRINCIPAL SECTORS } \\
\hline ICT Production & ELECOM & $30 t 33+64$ \\
\hline Manufacturing goods & MEXELEC & $15 t 29+34 t 37$ \\
\hline Non-Manufacturing goods & OTHERG & $A+B+C+E+F$ \\
\hline Financial and buss. services & FINBU & $\mathrm{J}+71 \mathrm{t} 74$ \\
\hline Distribution services & DIST & $50 t 52+60 t 63$ \\
\hline Personal services & PERS & $\mathrm{H}+\mathrm{O}$ \\
\hline \multicolumn{3}{|c|}{ TWO-SECTOR SPLITS } \\
\hline Agricultural & $A G R$ & AtB \\
\hline Non-Agricultural & non-AGR & Other Market \\
\hline Tradable & $T R A D$ & AtC $+30 \mathrm{t} 33+$ MEXELEC + $51+$ FINBU +60t63 \\
\hline Non-Tradable & non-TRAD & Other Market \\
\hline Investment & INV & $30 \mathrm{t} 33+M I n v+\lambda_{\text {inter }} M I n t+\lambda_{\text {ter }}(F I N B U+D I S T+64)$ \\
\hline Consumption & CONS & Other Market \\
\hline
\end{tabular}

Notes: Minves and Minter stand for intermediate and investment manufacturing. The percentages $\lambda_{\text {inter }}$ and $\lambda_{\text {ter }}$ state for the fraction of the final use devoted to investment calculated from the WIOD Input-Output tables.

TAB. 2-THREE INPUT MODEL: ALLEN ELASTICITIES AND CSC HYPOTHESIS

\begin{tabular}{lcccr}
\hline & \multicolumn{1}{c}{$\sigma_{\text {SU }}$} & $\sigma_{\text {SK }}$ & $\sigma_{U K}$ & \multicolumn{1}{c}{ CSC } \\
\hline MARKT & $1.826(0.275)$ & $\begin{array}{c}-0.503(0.423) \\
\text { PRINCIPAL SECTORS }\end{array}$ & $1.004(0.370)$ & $-1.507[-2.219 ;-0.501]$ \\
ELECOM & $1.532(0.483)$ & $0.836(0.236)$ & $0.393(0.125)$ & $0.443[-0.103 ; 1.008]$ \\
MEXELEC & $1.275(0.470)$ & $1.079(0.377)$ & $0.504(0.116)$ & $0.575[-0.249 ; 1.168]$ \\
OTHERG & $5.443(2.011)$ & $-0.798(0.584)$ & $0.388(0.209)$ & $-1.186[-2.654 ;-0.068]$ \\
FINBU & $2.107(0.514)$ & $1.161(0.374)$ & $0.094(0.303)$ & $1.066[-0.137 ; 2.009]$ \\
DIST & $1.925(0.391)$ & $0.065(0.515)$ & $0.186(0.180)$ & $-0.121[-1.121 ; 1.127]$ \\
PERS & $1.027(0.279)$ & $-0.538(0.306)$ & $0.568(0.123)$ & $-1.106[-1.597 ;-0.515]$ \\
& & TWO-SECTOR SPLITS & & \\
AGR & $2.569(0.985)$ & $0.384(0.303)$ & $0.332(0.123)$ & $0.051[-0.590 ; 0.601]$ \\
non-AGR & $1.660(0.232)$ & $-0.411(0.368)$ & $0.781(0.176)$ & $-1.193[-1.664 ;-0.101]$ \\
TRAD & $1.595(0.232)$ & $-0.552(0.380)$ & $1.180(0.257)$ & $-1.763[-2.183 ;-0.955]$ \\
non-TRAD & $2.043(0.489)$ & $-0.901(0.566)$ & $0.791(0.177)$ & $-1.692[-2.359 ;-0.052]$ \\
INV & $1.371(0.214)$ & $0.073(0.224)$ & $0.245(0.113)$ & $-0.172[-0.634 ; 0.381]$ \\
CONS & $2.153(0.250)$ & $-0.893(0.279)$ & $1.194(0.231)$ & $-1.986[-2.458 ;-1.073]$ \\
\hline
\end{tabular}

Notes: AES are computed at average period shares. Bootstrapped standard errors are in parenthesis. Last column is the AES between skilled labor and capital minus the AES between unskilled labor and capital. The CSC holds if the previous difference is negative. The numbers inside brackets are $90 \%$ bootstrapped percentile band, which correspond to $5 \%$ significance if the band is employed for one-side testing. 
TAB.3 - THREE INPUT MODEL: BIAS OF TECHNICAL CHANGE AND SBTC HYPOTHESIS

\begin{tabular}{lcccc}
\hline & $\boldsymbol{\beta}_{\mathrm{ST}}$ & $\boldsymbol{\beta}_{\mathrm{UT}}$ & $\boldsymbol{\beta}_{\mathrm{KT}}$ & $\mathrm{SBTC}$ \\
\hline MARKT & $0.004(0.000)$ & $-0.008(0.000)$ & $0.004(0.000)$ & $0.012[0.011 ; 0.014]$ \\
& & PRINCIPAL SECTORS & & \\
ELECOM & $0.005(0.001)$ & $-0.013(0.001)$ & $0.004(0.001)$ & $0.018[0.016 ; 0.019]$ \\
MEXELEC & $0.004(0.000)$ & $-0.008(0.000)$ & $0.004(0.000)$ & $0.013[0.012 ; 0.014]$ \\
OTHERG & $0.002(0.000)$ & $-0.004(0.001)$ & $0.002(0.000)$ & $0.007[0.005 ; 0.008]$ \\
FINBU & $0.007(0.001)$ & $-0.009(0.001)$ & $0.002(0.001)$ & $0.017[0.013 ; 0.020]$ \\
DIST & $0.003(0.001)$ & $-0.010(0.001)$ & $0.007(0.001)$ & $0.013[0.011 ; 0.017]$ \\
PERS & $0.004(0.001)$ & $-0.006(0.001)$ & $0.002(0.000)$ & $0.010[0.009 ; 0.013]$ \\
& & TWO-SECTOR SPLITS & & \\
AGR & $0.003(0.000)$ & $-0.003(0.001)$ & $0.000(0.001)$ & $0.006[0.004 ; 0.007]$ \\
non-AGR & $0.005(0.000)$ & $-0.009(0.000)$ & $0.004(0.000)$ & $0.013[0.012 ; 0.015]$ \\
TRAD & $0.005(0.000)$ & $-0.008(0.000)$ & $0.003(0.000)$ & $0.013[0.012 ; 0.014]$ \\
non-TRAD & $0.004(0.001)$ & $-0.008(0.001)$ & $0.004(0.000)$ & $0.012[0.011 ; 0.014]$ \\
INV & $0.006(0.001)$ & $-0.011(0.000)$ & $0.005(0.000)$ & $0.016[0.015 ; 0.018]$ \\
CONS & $0.005(0.000)$ & $-0.008(0.000)$ & $0.003(0.000)$ & $0.013[0.012 ; 0.014]$ \\
\hline N & & &
\end{tabular}

Notes: The numbers in the first four columns are the estimated bias of technical change, with bootstrapped standard errors in parenthesis. The last column collects the difference between the two labor biases. The SBTC hypothesis holds if the difference is positive. Parenthesis show the $90 \%$ percentile bootstrapped band for the difference, which corresponds to $5 \%$ significance to test one-sided hypothesis

TAB. 4 - THREE INPUT MODEL: FACTORS BEHIND THE CHANGE IN THE SKILL PREMIUM

\begin{tabular}{|c|c|c|c|c|c|c|}
\hline \multirow[t]{2}{*}{$\%$} & \multicolumn{2}{|c|}{ QUANTITY EFFECT } & \multicolumn{2}{|c|}{ TECH. EFFECT } & \multicolumn{2}{|c|}{ TOTAL CHANGE } \\
\hline & Labor & Capital & Labor & Capital & MODEL & DATA \\
\hline MARKT & -101 & 79 & 83 & -25 & 37 & 36 \\
\hline \multicolumn{7}{|c|}{ PRINCIPAL SECTORS } \\
\hline ELECOM & -107 & -42 & 141 & 18 & 10 & 11 \\
\hline MEXELEC & -72 & -12 & 89 & 8 & 12 & 18 \\
\hline OTHERG & -35 & 43 & 21 & -12 & 17 & 12 \\
\hline FINBU & -12 & -56 & 89 & 7 & 27 & 29 \\
\hline DIST & -40 & 8 & 66 & -4 & 29 & 28 \\
\hline PERS & -157 & 123 & 118 & -38 & 46 & 40 \\
\hline \multicolumn{7}{|c|}{ TWO-SECTOR SPLITS } \\
\hline$A G R$ & -55 & -3 & 64 & 0 & 7 & 3 \\
\hline non-AGR & -107 & 72 & 99 & -25 & 39 & 37 \\
\hline TRAD & -167 & 104 & 120 & -27 & 31 & 29 \\
\hline non-TRAD & -86 & 77 & 83 & -34 & 39 & 37 \\
\hline INV & -114 & 27 & 110 & -11 & 11 & 23 \\
\hline CONS & -128 & 102 & 99 & -34 & 40 & 36 \\
\hline
\end{tabular}

Notes: Decomposition of the percentage change in the skill premium between 1980 and 2005 predicted in the model into the labor quantity, capital quantity, and non-neutral technical change effects. The last two columns provide the percentage change in the model and in the data. 
TAB. 5- THREE INPUT MODEL: FACTORS BEHIND THE CHANGE IN THE SHARE OF SKILLED LABOR INCOME RELATIVE TO THE UNSKILLED

\begin{tabular}{lrrrrrr}
\hline$\%$ & \multicolumn{2}{c}{ QUANTITY EFFECT } & \multicolumn{2}{c}{ TECH. EFFECT } & \multicolumn{2}{c}{ TOTAL CHANGE } \\
& Labor & Capital & Labor & Capital & MODEL & DATA \\
\hline MARKT & -26 & 79 & 83 & -25 & 112 & 111 \\
ELECOM & \multicolumn{7}{c}{ PRINCIPAL SECTORS } & & & \\
MEXELEC & 11 & -42 & 141 & 18 & 128 & 129 \\
OTHERG & 14 & -12 & 89 & 8 & 99 & 104 \\
FINBU & 16 & 43 & 21 & -12 & 67 & 63 \\
DIST & 52 & -56 & 89 & 7 & 92 & 94 \\
PERS & 18 & 8 & 66 & -4 & 88 & 87 \\
& -113 & 123 & 118 & -38 & 89 & 84 \\
AGR & & TWO-SECTOR SPLITS & & & \\
non-AGR & 27 & -3 & 64 & 0 & 89 & 85 \\
TRAD & -33 & 72 & 99 & -25 & 113 & 111 \\
non-TRAD & -74 & 104 & 120 & -27 & 124 & 121 \\
INV & -33 & 77 & 83 & -34 & 93 & 90 \\
CONS & -6 & 27 & 110 & -11 & 119 & 131 \\
\hline NON & -55 & 102 & 99 & -34 & 112 & 108 \\
\hline
\end{tabular}

Notes: Decomposition of the percentage change in the skilled labor share of income relative to the unskilled between 1980 and 2005 predicted in the model into the labor quantity, capital quantity, and non-neutral technical change effects. The last two columns provide the percentage change in the model and in the data.

TAB. 6 - FOUR INPUT MODEL: ALLEN ELASTICITIES AND CSC

\begin{tabular}{lcccccccc}
\hline & $\sigma_{S U}$ & $\sigma_{S I}$ & $\sigma_{S N}$ & $\sigma_{U I}$ & $\sigma_{U N}$ & $\sigma_{I N}$ & ICT-CSC & NonICT-CSC \\
\hline MARKT & 1.61 & -0.15 & -0.63 & 1.36 & 0.88 & 0.09 & -1.51 & -1.50 \\
& $(0.15)$ & $(0.66)$ & $(0.18)$ & $(0.35)$ & $(0.13)$ & $(0.44)$ & {$[-2.95 ;-0.06]$} & {$[-1.87 ;-0.95]$} \\
ELECOM & 1.67 & 2.04 & -0.14 & 0.36 & 0.44 & 0.87 & 1.68 & -0.58 \\
& $(0.49)$ & $(0.63)$ & $(0.50)$ & $(0.34)$ & $(0.31)$ & $(0.46)$ & {$[0.21 ; 3.22]$} & {$[-1.94 ; 0.79]$} \\
MEXELEC & 1.69 & 0.39 & 0.80 & -0.40 & 0.49 & 3.38 & 0.79 & 0.31 \\
& $(0.79)$ & $(5.72)$ & $(0.65)$ & $(1.78)$ & $(0.20)$ & $(1.68)$ & {$[-11.49 ; 12.28]$} & {$[-1.05 ; 1.76]$} \\
OTHERG & 4.69 & -2.34 & -0.59 & 3.51 & 0.42 & -0.77 & -5.85 & -1.01 \\
& $(0.91)$ & $(5.23)$ & $(0.36)$ & $(1.14)$ & $(0.15)$ & $(0.61)$ & {$[-16.41 ; 4.01]$} & {$[-1.75 ;-0.23]$} \\
FINBU & 2.92 & -2.02 & 1.21 & 3.00 & -0.26 & 3.08 & -5.02 & 1.47 \\
& $(0.53)$ & $(0.95)$ & $(0.40)$ & $(0.84)$ & $(0.36)$ & $(0.90)$ & {$[-7.22 ;-2.04]$} & {$[-0.17 ; 2.72]$} \\
DIST & 2.13 & 2.96 & -1.24 & -0.14 & 0.60 & 1.67 & 3.10 & -1.84 \\
& $(0.27)$ & $(0.84)$ & $(0.27)$ & $(0.31)$ & $(0.11)$ & $(0.55)$ & {$[-0.01 ; 4.90]$} & {$[-1.69 ;-0.10]$} \\
PERS & 0.99 & -1.66 & -0.52 & 1.73 & 0.43 & 4.71 & -3.40 & -0.95 \\
& $(0.25)$ & $(2.88)$ & $(0.33)$ & $(1.20)$ & $(0.15)$ & $(1.68)$ & {$[-9.61 ; 4.69]$} & {$[-1.67 ;-0.10]$} \\
\hline
\end{tabular}

Notes: AES are computed at average period shares (bootstrapped standard errors in parenthesis). Last two columns show the AES between skilled labor and (ICT and non-ICT) capital minus the AES between unskilled labor and (ICT and non-ICT) capital. The CSC holds if the previous difference is negative. The numbers inside brackets are $90 \%$ bootstrapped percentile band, which correspond to 5\% significance if the band is employed for one-side testing. 
TAB.7 - FOUR INPUT MODEL: BIAS OF TECHNICAL CHANGE AND SBTC HYPOTHESIS

\begin{tabular}{lccccc}
\hline & $\beta_{\text {ST }}$ & $\beta_{U T}$ & $\beta_{\text {IT }}$ & $\beta_{\text {NT }}$ & SBTC \\
\hline MARKT & 0.004 & -0.007 & 0.003 & 0.000 & 0.011 \\
& $(0.001)$ & $(0.001)$ & $(0.000)$ & $(0.000)$ & {$[0.010 ; 0.014]$} \\
ELECOM & & \multicolumn{2}{c}{ PRINCIPAL SECTORS } & & \\
& 0.006 & -0.013 & 0.003 & 0.004 & 0.019 \\
MEXELEC & $(0.001)$ & $(0.001)$ & $(0.001)$ & $(0.001)$ & {$[0.016 ; 0.022]$} \\
& 0.004 & -0.010 & 0.001 & 0.005 & 0.014 \\
OTHERG & $(0.002)$ & $(0.003)$ & $(0.001)$ & $(0.001)$ & {$[0.006 ; 0.021]$} \\
& 0.002 & -0.003 & 0.000 & 0.000 & 0.005 \\
FINBU & $(0.001)$ & $(0.001)$ & $(0.000)$ & $(0.000)$ & {$[0.003 ; 0.007]$} \\
& -0.001 & -0.005 & 0.002 & 0.002 & 0.006 \\
DIST & $(0.002)$ & $(0.001)$ & $(0.001)$ & $(0.001)$ & {$[0.001 ; 0.012]$} \\
& 0.005 & -0.010 & 0.003 & 0.003 & 0.015 \\
PERS & $(0.001)$ & $(0.003)$ & $(0.000)$ & $(0.001)$ & {$[0.013 ; 0.018]$} \\
& 0.004 & -0.005 & 0.000 & 0.001 & 0.009 \\
& $(0.001)$ & $(0.001)$ & $(0.000)$ & $(0.000)$ & {$[0.006 ; 0.013]$}
\end{tabular}

Notes: The numbers in the first four columns are the estimated bias of technical change (bootstrapped standard errors in parenthesis). The fifth column is difference between the technical bias of the two labor inputs. The SBTC hypothesis holds if the difference is strictly positive. The numbers inside parenthesis are the $90 \%$ percentile bootstrapped band for the estimated difference, which corresponds to 5\% significance to test onesided hypothesis.

TAB. 8- FOUR INPUTS MODEL: FACTORS BEHIND THE CHANGE IN THE SKILL PREMIUM

\begin{tabular}{lrrrrrrr}
\hline$\%$ & \multicolumn{3}{c}{ QUANTITY EFFECT } & \multicolumn{2}{c}{ TECH. EFFECT } & \multicolumn{2}{c}{ TOTAL } \\
& Labor & ICT & Non-ICT & Labor & Capital & MODEL & DATA \\
\hline MARKT & -141 & 19 & \multicolumn{7}{c}{74} & 100 & -15 & 37 & 36 \\
& & \multicolumn{7}{c}{ PRINCIPAL SECTORS } & & & \\
ELECOM & -111 & -47 & 29 & 141 & 0 & 12 & 11 \\
MEXELEC & -69 & -12 & -4 & 88 & 11 & 14 & 18 \\
OTHERG & -32 & 1 & 25 & 24 & -2 & 16 & 12 \\
FINBU & -91 & 152 & 3 & 1 & -33 & 32 & 29 \\
DIST & -108 & -25 & 164 & 89 & -77 & 43 & 28 \\
PERS & -194 & 39 & 102 & 130 & -32 & 44 & 40 \\
\hline
\end{tabular}

Notes: Decomposition of the percentage change in the skilled premium between 1980 and 2005 predicted in the model into the labor quantity, (ICT and non-ICT) capital quantity, and non-neutral technical change effects. The last two columns provide the percentage change in the model and in the data. 
TAB. 9- FOUR INPUTS MODEL: FACTORS BEHIND THE CHANGE IN THE SKILLED LABOR SHARE OF INCOME RELATIVE TO THE UNSKILLED

\begin{tabular}{lrrrrrrr}
\hline$\%$ & \multicolumn{2}{c}{ QUANTITY EFFECT } & \multicolumn{2}{c}{ TECH. EFFECT } & \multicolumn{2}{c}{ TOTAL } \\
\hline & Labor & ICT & Non-ICT & Labor & Capital & MODEL & DATA \\
\hline MARKT & -66 & 19 & \multicolumn{7}{c}{74} & 100 & -15 & 112 & 111 \\
ELECOM & 7 & -47 & 29 & 141 & 0 & 130 & 129 \\
MEXELEC & 17 & -12 & -4 & 88 & 11 & 100 & 104 \\
OTHERG & 18 & 1 & 25 & 24 & -2 & 66 & 63 \\
FINBU & -26 & 152 & 3 & 1 & -33 & 97 & 94 \\
DIST & 9 & 10 & 17 & 62 & -12 & 86 & 87 \\
PERS & -151 & 39 & 102 & 130 & -32 & 88 & 84 \\
\hline NESIPAL SECTORS
\end{tabular}

Notes: Decomposition of the percentage change in the skilled labor share of income relative to the unskilled between 1980 and 2005 predicted in the model into the labor quantity, (ICT and non-ICT) capital quantity, and non-neutral technical change effects. The last two columns provide the percentage change in the model and in the data. 
FIG.1- RELATIVE QUANTITY OF SKILLED HOURS. SKILL PREMIUM, AND INCOME SHARE OF SKILLED LABOR RELATIVE TO THE UNSKILLED: 1970-2005

RELATIVE QUANTITY OF SKILLED HOURS

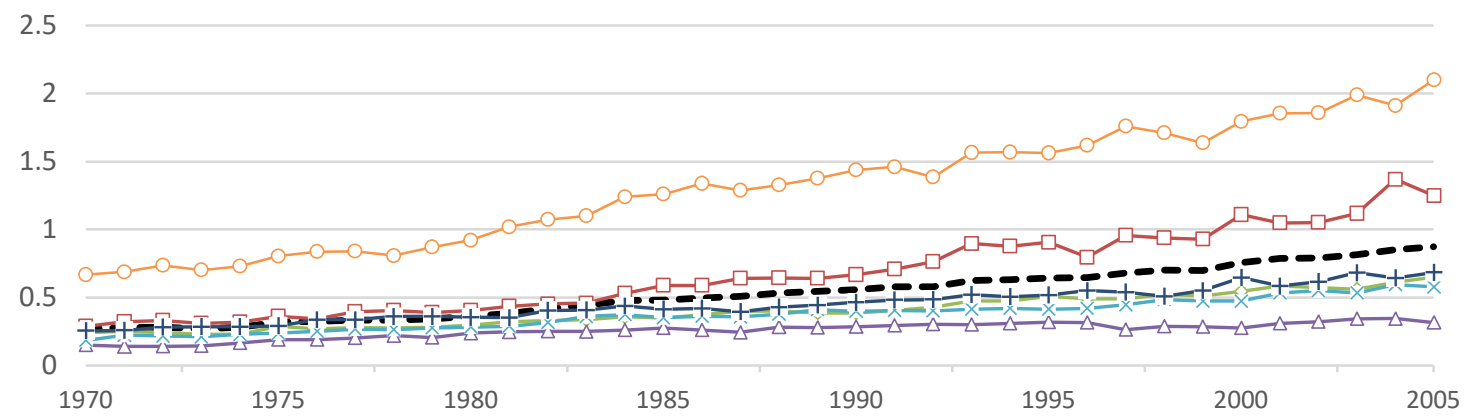

SKILL PREMIUM

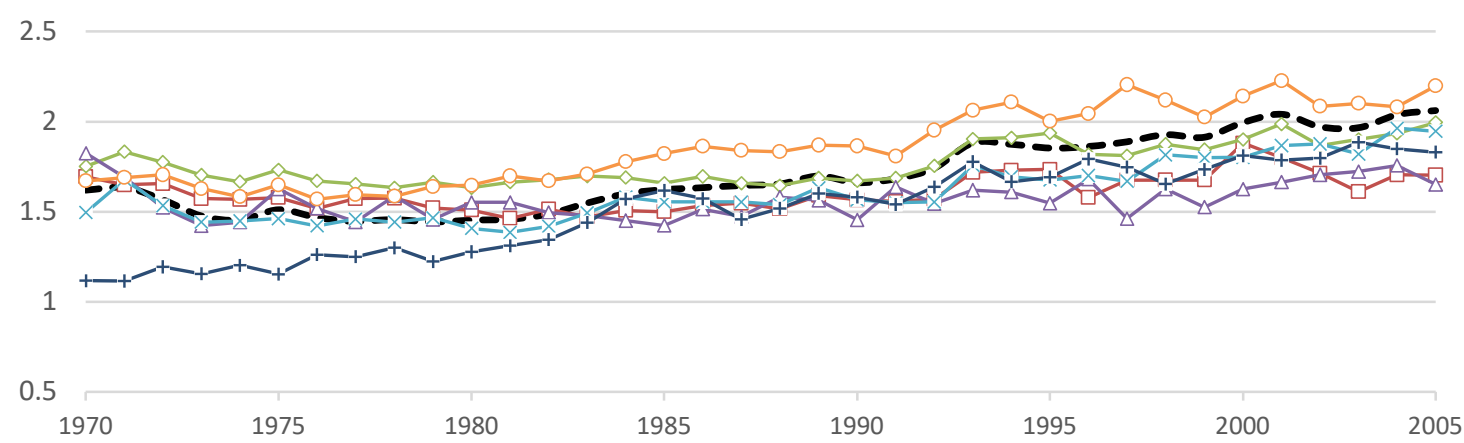

SKILLED LABOR INCOME SHARE RELATIVE TO UNSKILLED LABOR INCOME SHARE

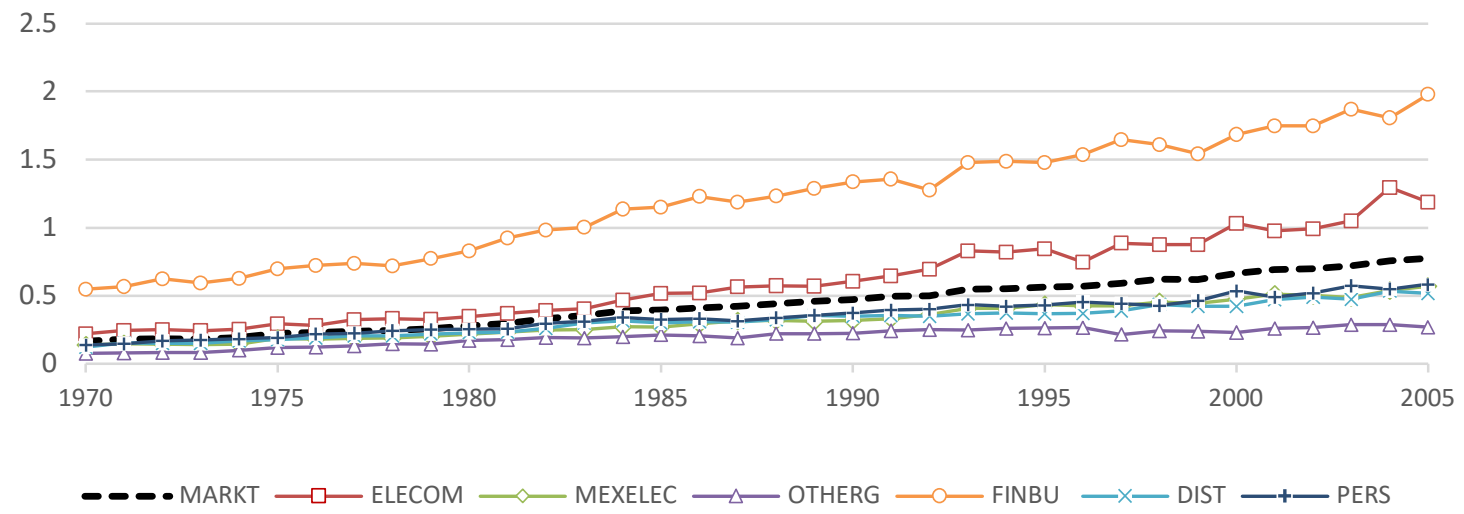

Notes: MARKT: aggregate (market) economy; ELECOM: ICT production; MEXELEC: Manufacturing goods (excluding electrical); OTHEG: Non-manufacturing goods; FINBU: Financial and business services; DIST: Distribution services; PERS: Personal services. 
FIG.2 -FACTOR INTENSITIES: 1970-2005

LABOR SHARE OF INCOME

1

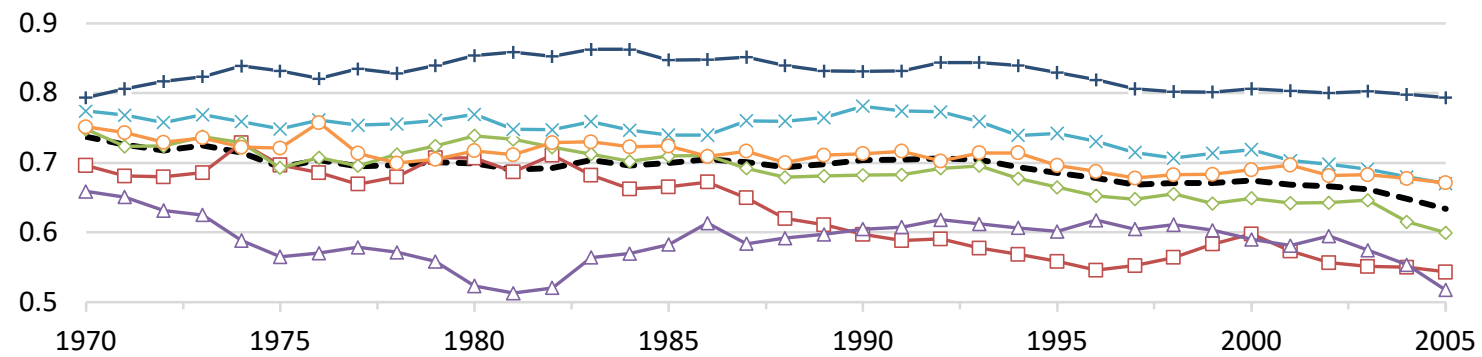

SKILLED LABOR SHARE OF INCOME

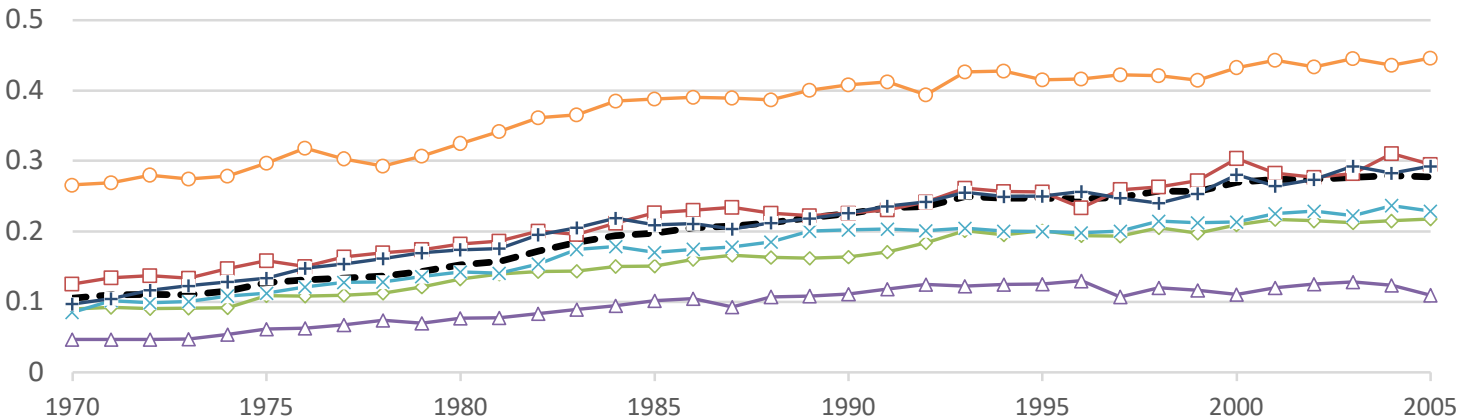

CAPITAL SHARE OF INCOME

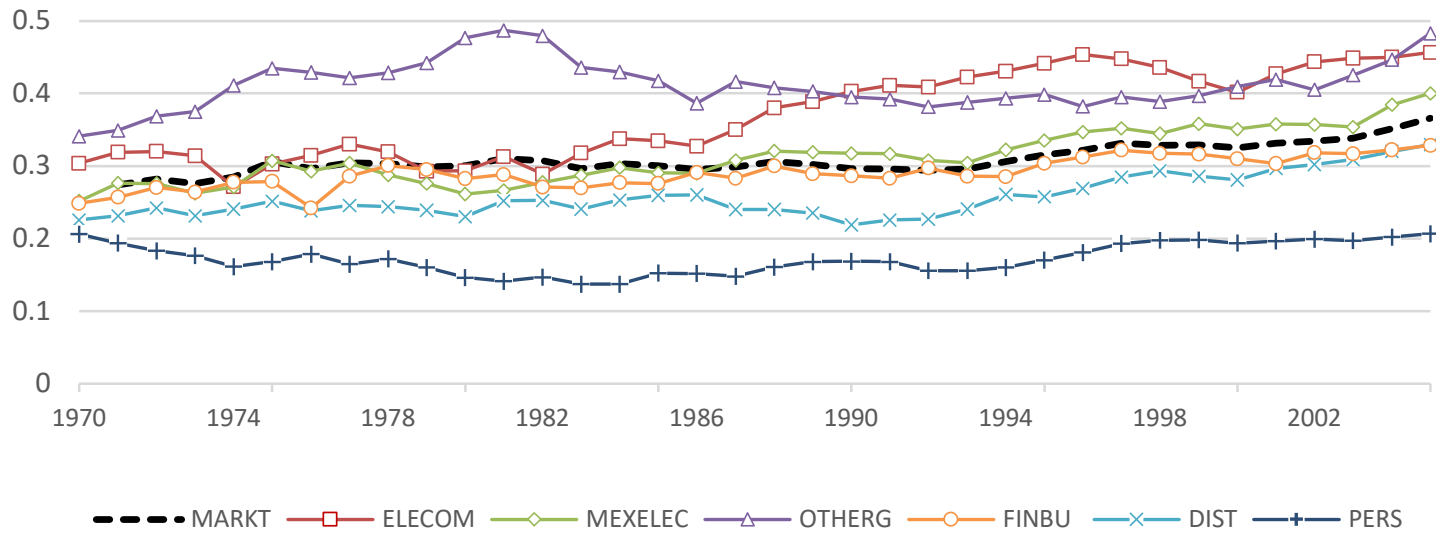

Notes: MARKT: aggregate (market) economy; ELECOM: ICT production; MEXELEC: Manufacturing goods (excluding electrical); OTHEG: Non-manufacturing goods; FINBU: Financial and business services; DIST: Distribution services; PERS: Personal services. 